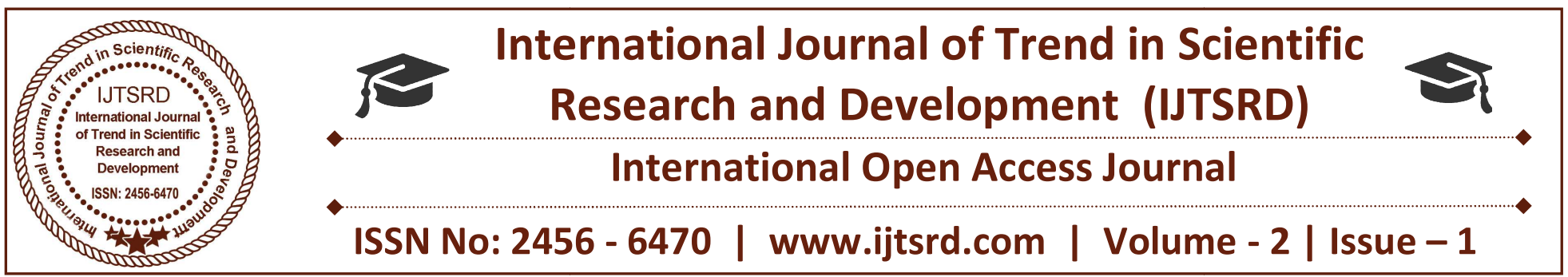

\title{
Serial Manipulator Design for an AG-Robot
}

\author{
Mr. K. Rajesh \\ Assistant Professor, Stanley College of Engineering \\ and Technology for Women, Hyderabad
}

\begin{abstract}
At present observation all the industries are looking at Robotization, to increase productivity and quality. The industrial robots of today may not look the least bit like a human being although all the research is directed to provide more and more anthropomorphic and humanlike features and super-human capabilities. in these Robots can perform desired tasks in unstructured environments without continuous human guidance. Many kinds of robots are autonomous to some degree.
\end{abstract}

In this paper explains about pick and Place Robot design with agriculture application which runs on human guidance. For this two servo motors are used to control the robot. Micro Control of the robotic arm has been achieved successfully by using servo motors or dc motors. The microcontrollers implement inverse kinematics algorithms and implement position control on the motors.

Keywords: RCRV, Unstructured, Autonomy, Space exploration, Kinematics, Provision, Inbuilt logics, Automation, Anthropomorphic

\section{INTRODUCTION}

Robotics is the branch of engineering science \& Technology related to robots, and their design, manufacture, application, and structural disposition. Robotics is related to electronics, mechanics, and software. Robotics research today is focused on developing systems that exhibit modularity, flexibility, redundancy, fault-tolerance, a general and extensible software environment and seamless connectivity to other machines, some researchers focus on completely automating a manufacturing process or a task, by providing sensor based intelligence to the robot arm, while others try to solidify the analytical foundations on which many of the basic concepts in robotics are built.

\section{DIFFICULTIES IN DESIGN:}

Serial manipulators are the most commonly used robots designed by series of links connected by motors actuated joints that extend from base to end effector .There are certain difficulties associated with building a tele-operated robotic vehicle with an embedded robotic arm. Firstly, the problem is integrating the units to form a working machine. Secondly, the problem is using the right actuator (pneumatic, stepper motor, RC servo etc). And thirdly, the problem is appropriate communication protocol to implement and also the choice of material (aluminum, steel, carbon fiber, plastic etc). The most important part of the Remote-Controlled Robotic Vehicle (RCRV) is the Joint Actuator.

\section{RCRV:}

Its choice depends on the maximum weight the arm can carry, response of the arm to command, availability of the actuator, ease of use and price. In this work, a miniature Remote Control Robotic Vehicle (RCRV) with four degree of freedom (4 DOF) robotic arm has been designed and developed .The objective is to produce a basic model with standard sensors and a robotic arm with the plank acting as a base but there will be no mobility of the base. It is also intended that the structure of the robot should be simple to facilitate easy adaptation and upgrading. The housing is designed to create three distinct layers within the RCRV to separate elements 
of the robot, thus leaving room to add more devices when completed. The bottom layer was designed for battery housing and mechanical hardware, such as gears and motors, the middle layer to contain the main interface electronics, and the top layer for the arm and external devices.

\section{CONFIGURATIONS OF ROBOTIC ARM:}

\section{Cartesian robot / Gantry robot:}

Used for pick and place work, application of sealant, assembly operations, handling machine tools and arc welding. It's a robot whose arm has three prismatic joints, whose axes are coincident with a Cartesian coordinator.

\section{Cylindrical robot:}

Used for assembly operations, handling at machine tools, spot welding, and handling at die casting machines. It's a robot whose axes form a cylindrical coordinate system.

\section{Spherical robot / Polar robot:}

Used for handling machine tools, spot welding, die casting, fettling machines, gas welding and arc welding. It's a robot whose axes form a polar coordinate system.

\section{SCARA robot:}

Used for pick and place work, application of sealant, assembly operations and handling machine tools. This robot features two parallel rotary joints to provide compliance in a plane.

\section{Articulated robot:}

Used for assembly operations, die casting, fettling machines, gas welding, arc welding and spray painting. It's a robot whose arm has at least three rotary joints.

\section{Parallel robot:}

One use is a mobile platform handling cockpit flight simulators. It's a robot whose arms have concurrent prismatic or rotary joints.

\section{Anthropomorphic robot:}

It is shaped in a way that resembles a human hand, i.e. with independent fingers and thumbs.
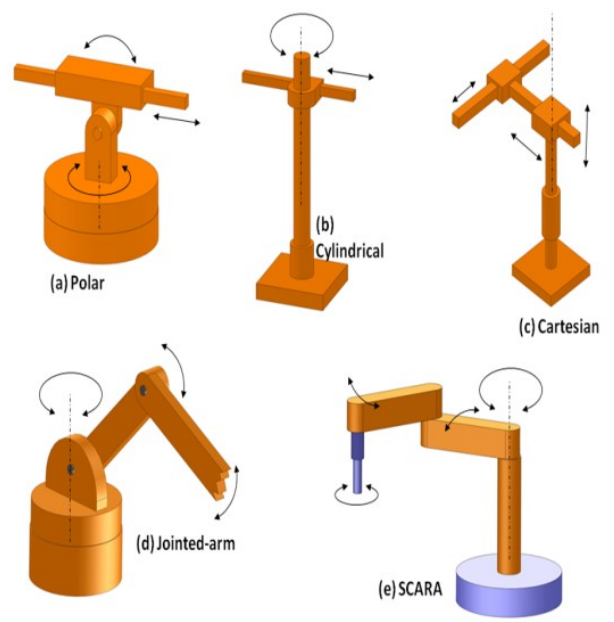

Figure 1: Robotic arm Configuration

\section{DEGREE OF FREEDOM}

The number of DOF that a manipulator possesses is the number of independent position variables that would have to be specified in order to locate all parts of the mechanism; it refers to the number of different ways in which a robot arm can move in the particular direction.

In the case of typical industrial robots, because a manipulator is usually an open kinematic chain, and because each joint position is usually defined with a single variable, the number of joints equals the number of degrees of freedom.

We can use the arm to get the idea of degrees of freedom. Keeping the arm straight, moving it from shoulder, we can move in three ways. Up-and-down movement is called pitch. Movement to the right and left is called yaw. By rotating the whole arm as screwdriver is called roll. The shoulder has three degrees of freedom. They are pitch, yaw and roll.

$$
\begin{aligned}
\mathrm{DOF}= & \lambda(\mathrm{N}-\mathrm{J}-1)+\sum_{i=1}^{j} \mathrm{Fi} \\
& \text { Where } \\
& \mathrm{N}=\text { total no of links including fixed } \\
& \mathrm{J}=\text { joints } \\
& \mathrm{F}_{\mathrm{i}}=\text { degrees of freedom at the } \mathrm{i}^{\text {th }} \text { joint }
\end{aligned}
$$

In serial manipulators with a fixed base, a free endeffector and one link connected by a joint, from the above equation $\mathrm{N}=\mathrm{J}+1$ and $\mathrm{DOF}=\sum_{i=1}^{j} \mathrm{~F} i$. If all the actuated joints are one- degree-of freedom joints, then $\mathrm{J}=$ dof.

$\mathrm{N}=2$

$\mathrm{J}=1$

Therefore DOF $=\sum_{i=1}^{j} \mathrm{~F} i=1+1=2 \mathrm{DOF}$ 


\section{TASKS TO BE PERFORMED}

The various tasks which a pick and place robot can perform are as follows:-

Robot pick-and-place: The use of robots for placing products in cartons and transfer of cartons and products between different stations in the packaging lines is very common in all industries. High speed pick-and-place robots for placing small items like candy and cookies in packages are often combined with a visual observation system for identifying products.

Handling of flexible packages: Flexible packaging material is the generic term for soft packages made of film, foil or paper sheeting. Popular forms are standup pouches, bags, sachets and envelopes. These packages are often formed, filled and sealed in a vertical or horizontal form-fill-seal machine. The package is then finally put into a case by top loading.

\section{PARTS USED:}

Various components of appropriate specifications should be selected so as to complete the fabrication and assembly of the Robot. If the selection is not done properly then the proper working of the robot cannot be obtained. It includes the parts like selection of actuators, motors, sensors etc. Thus the selection procedure of various components is also an important issue for the project work

Material: Aluminum

Battery: AMPTEK AT 12v 1.3 Ah

Motors: RF 500 TB 12560

CALCULATIONS FOR MANIPULATOR

DIMENSIONS OF GEAR BOX(BASE)

Gear box of Ag-Robotic arm contains a cubical shield in which gear and pinion are fixed to the motors, through which motion is attained for links to move.

Dimensions of the gear box are $65 \times 70$ X $1 \mathrm{~mm}$ (one side dimensions)

There are 4 sides for gear box

Now

- Total area of gear box sides = length* breadth*height $=65 * 70=4550 \mathrm{~mm}^{2}$

- Total volume $=65 * 70 * 1=4550 \mathrm{~mm}^{3}$

Mass of gear box $=$ volume $*$ density $=$ $4550 * 2.70 / 1000=18.2 \mathrm{gms}$

\section{LINK DIMENSIONS:}

- Volume $=34 * 105^{*} 1=3570 \mathrm{~mm}^{3}$

- Weight $=3570 * 2.7 / 1000=9.63 \mathrm{gms}$

\section{DIMENSIONS FOR THE PLATE:}

- Area of the rectangle = length $*$ breadth $=$ $73 \mathrm{~mm} * 74 \mathrm{~mm}=5402 \mathrm{~mm}^{2}$

- $\quad$ Area of triangle $=1 / 2 *$ base $*$ height $=1 / 2 * 1.9 * 3.7$ $=3.5 \mathrm{~cm}^{2}$

- Area of 2 triangles $=2 * 3.5 \mathrm{~cm}=7.03 \mathrm{~cm}^{2}=703$ $\mathrm{mm}^{2}$

- $\quad$ Total area of the plate $=$ area of rectangle - area of 2 triangles $=5402-703=4699 \mathrm{~mm}^{2}$

There are 2 plates

- Therefore $=2 * 4699=9398 \mathrm{~mm}^{2}$

- Volume $=4699 * 270 / 1000=12.68 \mathrm{gm}$

- Volume $=73 \mathrm{~mm}^{*} 35 \mathrm{mmm}^{*} 1=2555 \mathrm{~mm}^{3}$

- Total volume $=9398 \mathrm{~mm}-2555 \mathrm{~mm}=1193 \mathrm{~mm}^{3}$

- Weight $=11953 * 2.70 / 1000=320.27 \mathrm{gms}$

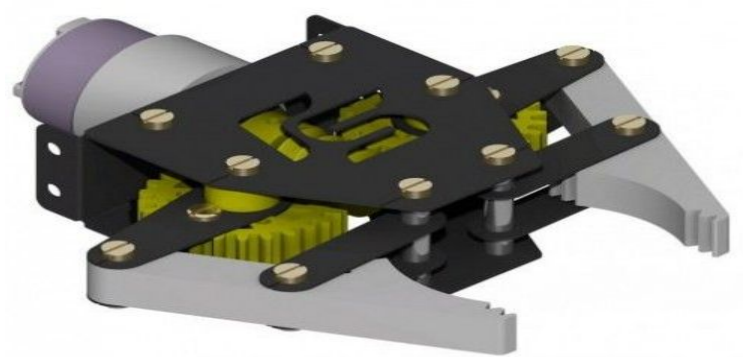

Figure 2: Gripper of Robotic arm

\section{TORQUE CALCULATION}

Every motor has a torque described in $\mathrm{kgcm}$ units. 1 $\mathrm{kg} \mathrm{cm}$ means that the motor can lift $1 \mathrm{~kg}$ weight on a distance of $1 \mathrm{~cm}$ from the axis of rotation, or $0.5 \mathrm{~kg}$ at the distance of $2 \mathrm{~cm}$ and so on. Using that knowledge and the fact that you are lifting $1 \mathrm{~kg}$ we can say that arm's length * $1 \mathrm{~kg}$ must be less than the maximal torque of the motor. The stronger the motor - the longer the arm can be. How strong motor you'll use depends on what length you need for your design.

$$
\begin{aligned}
& \text { Torque }=\text { force } * \text { length } \\
& \text { Force }=\mathrm{m}^{*} \mathrm{~g} \\
& \mathrm{~T}=400 \mathrm{~g} * 9.81 * 300 \mathrm{~mm}=1.17 \mathrm{~N} \mathrm{~m}=12 \mathrm{Kg} \mathrm{cm}
\end{aligned}
$$


This takes us fact that the manipulator can be able to lift $500 \mathrm{gm}$ weight at a distance of $24 \mathrm{~cm}$ from the axis of rotation.

A $500 \mathrm{gm}$ weight at the end of $300 \mathrm{~mm}$ distance from rotation gives $1.47 \mathrm{Nm}$ torque .

Torque $=500 \mathrm{~g} * 9.81 * 300 \mathrm{~mm}=1.47 \mathrm{Nm}$

Now total weight of the arm $=400 \mathrm{~g}$

Assuming the centre of gravity of the arm at $150 \mathrm{~mm}$, torque added is $0.5886 \mathrm{Nm}$

Torque $=150 \mathrm{~mm} * 400 \mathrm{~g}=0.5886 \mathrm{Nm}$

Total Torque $=1.47+0.5886 \mathrm{Nm}=2.058 \mathrm{Nm}$

Angular acceleration of arm can be obtained by the relation

Torque $=$ moment of inertia $*$ angular acceleration

\section{SELECTION OF MOTOR TO BE USED:}

As per the above torque calculation the motor has to produce a torque of $1.17 \mathrm{Nm}$ at $300 \mathrm{rpm}$ is required in order to give desired thrust. So the Motor RF -500TB12560 is suitable.

\section{CONCLUSION:}

The complete torque calculations for SERIAL MANIPULATOR of an AG-ROBOT are made in order to produce the desired thrust and selected a suitable range of Motor. The same can be carried to make a Model.

\section{REFERENCES}

1. RK Mittal and IJ Nagarath "Robotics and Control" BITS Pilani, 2003

2. Ratheesh Rajan "Foundation Studies for an Alternate Approach to Motion Planning of Dynamic Systems" M.S.E., the University of Texas at Austin, 2001

3. Nam Sun Wang, Department of Chemical \& Bimolecular Engineering, University of Maryland

4. www.robotis.com

5. www.asmedl.org/robotics

6. www.wikipedia.org/wiki/Robotics

7. http://www.robologix.com 